\title{
Office Based and Surgery Center
}

\author{
Denis G. Patterson
}

\section{Key Concepts}

- When a physician performs a procedure in his office, he/ she gets a global fee (which consists of a professional fee and a facility fee) from the insurance company.

- If a physician performs a procedure in a hospital or at an ambulatory surgery center, he/she only receives the professional fee.

- Pain management physicians can own ambulatory surgery centers and generate significant profits from them.

\section{Introduction}

An office-based pain management practice with a surgery center can be an effective business structure for optimizing revenue for pain management physicians. Most interventional pain management services can be provided in an office-based setting because they do not require significant clinical resources. However, some of the services must be performed at an ambulatory surgery center (ASC) or hospital. Most insurance companies pay for services in two ways: a professional fee for the physician and a facility fee for the location. If a physician performs a service in their office, he gets both of these payments in one lump sum that is referred to as a global fee. If he performs the service at an ASC or hospital, he receives only the professional component of the fee, and the ASC or hospital receives the facility component of the fee. So the physician receives less money

D.G. Patterson, MD $(\bowtie)$

Nevada Advanced Pain Specialists, Department of Pain Medicine, 10715 Double R Blvd, Ste 101, Reno, NV 89521, USA

e-mail: patterson@nvadvancedpain.com for a service he does not perform in his own office, and the facility payment to an ASC or hospital is usually much higher than the facility fee paid to the physician office. This is because the ASCs and hospitals are required to have significantly more fixed costs in order to be licensed as such entities.

Opportunities exist for pain management physicians to be owners of ASCs. Depending on state regulations, which vary widely for treatment of ASCs, a physician or group of physicians can join together to build or purchase an ASC. If the ASC's fixed costs can be effectively minimized, and the physicians involved in the ASC can effectively bring and build surgery and procedure volume in a consistent manner, the ASC can generate significant profits from the facility fees it earns. Depending on the exact legal structure and compensation arrangements, a physician who is a partner in an ASC can improve his revenue by performing appropriate cases in the ASC as opposed to a hospital. The physician and his office scheduling staff must be trained to know which procedures should be performed at which locations in order to optimize this opportunity.

\section{Emerging Concepts}

Practice development and management of the complexities of the clinical encounter is critical when deciding where to perform or the "site of service." Trends can be forecasted based on remuneration changes, both for the clinical provider payment and the facility payment. Hospitals traditionally are paid more than the ASC for facility fees, which vary based on the procedure.

\section{Suggested Reading}

1. ASIPP Fee Schedule. https://www.asipp.org/feeschedules.html.

2. Falowski SM, Pope JE, editors. Integrating pain treatment into your spine practice. New York: Springer; 2016. 